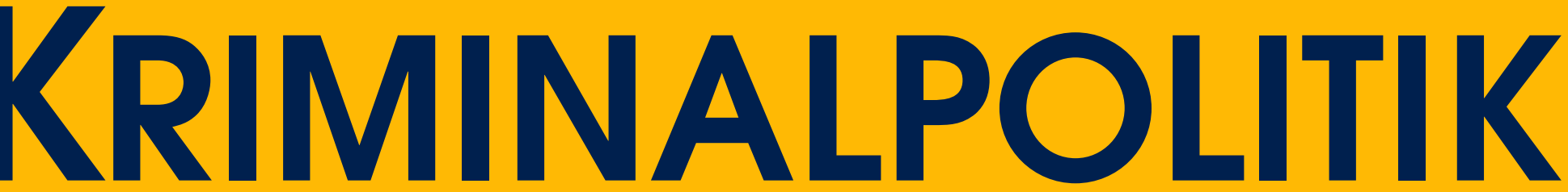
Forum fur Proxis, Polfitk und Wissenschaft

FORUM:

Uwe MUth off und Sefonie Mehrens uber die Notwendigkeit einer modernislerten Kronzeugen regelung

AOSSERD ENB

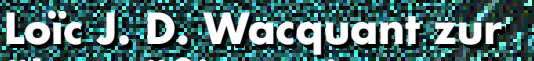

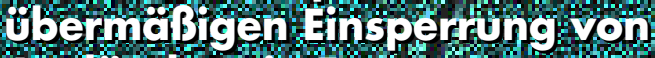

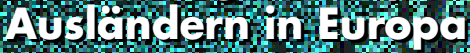

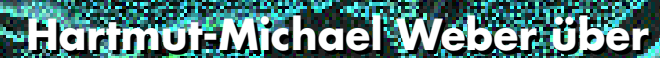
cie t uswirkungen of trejen

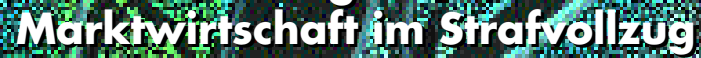

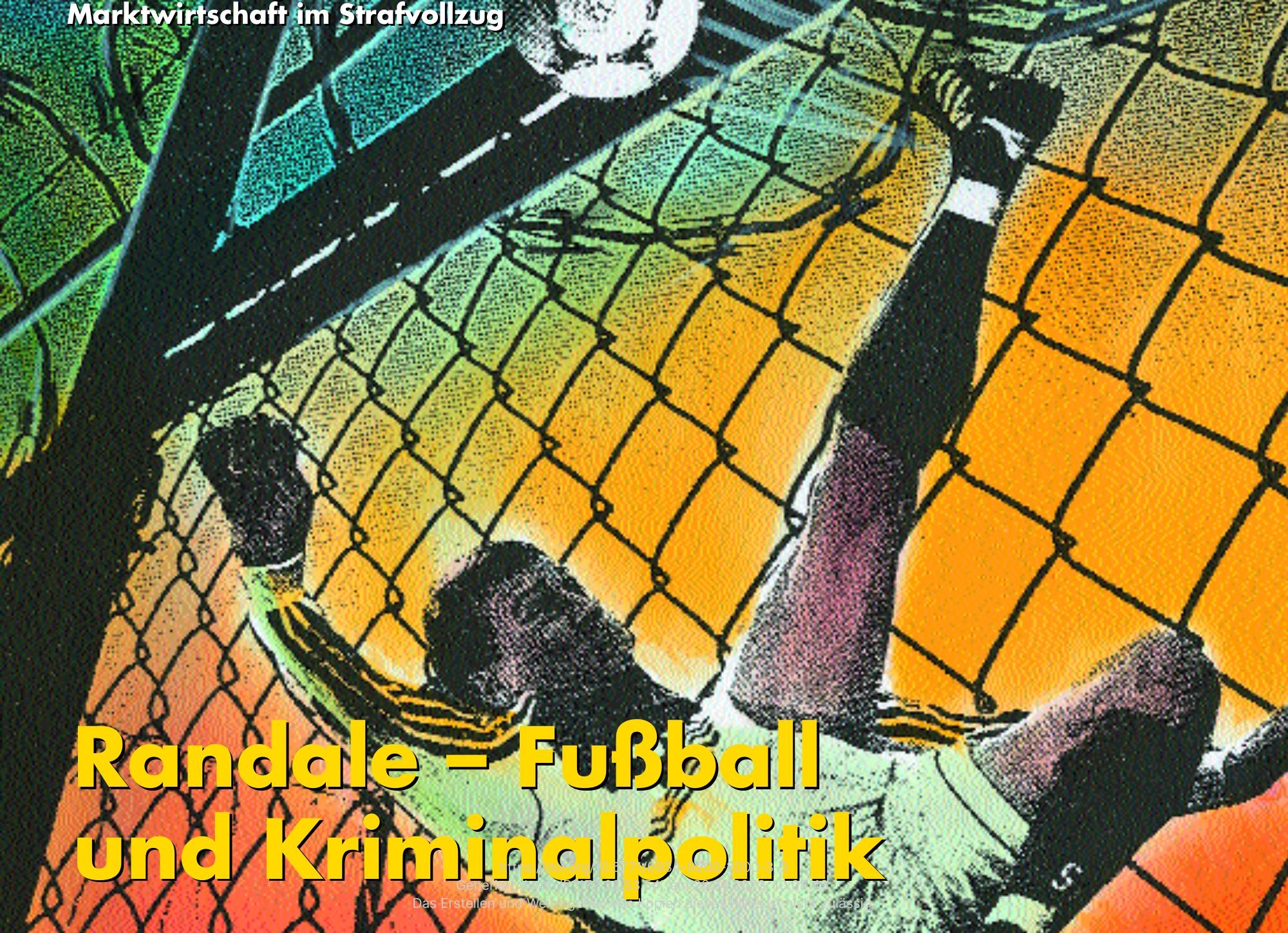




\section{IN DIESEM HEFT:}

\section{Europäisch}

Es war nicht so geplant, aber als ich mich an dieses Editorial setzte und mir dazu die Beiträge des Heftes noch einmal im Überblick ansah, fiel mir auf, daß es eine ungewöhnlich »internationale « Nummer geworden ist: Es geht los mit dem Gastbeitrag aus Kalifornien über Ausländer in europäischen Gefängnissen, weiter mit einem Vergleich der Kronzeugenregelung in Deutschland und Italien, mit der Überbelegung von Gefängnissen im internationalen Vergleich, einem Ein- und Ausblick in das europäische Polizeiund Strafrecht und endet mit einem (Titel-)Beitrag über die niederländische Politik im Umgang mit »Störungen der öffentlichen Ordnung « anläßlich der Fußball-Europameisterschaft. Für das nächste Heft planen wir übrigens ein Titelthema mit Berichten zur europäischen Strafpraxis.

Sicher war die Neue Kriminalpolitik schon immer international orientiert, aber wenn ich mich nicht irre, zeichnet sich nicht nur in unserer Zeitschrift eine Tendenz zur »Europäisierung « rechts- und kriminalpolitischer Debatten und Entwicklungen ab (wohingegen es - wie in anderen Bereichen auch - wenig Anzeichen einer wirklichen "Globalisierung " gibt, die mehr als die westlichen Industrienationen umfaßt). In Europa jedenfalls werden die Spielräume für nationale Sonderwege geringer. Leider vollzieht sich diese Entwicklung vor allem auf Kosten der (bisher nationalstaatlich garantierten) Menschen- und Bürgerrechte, auf Kosten der Rechte und

Mitwirkungsmöglichkeiten Einzelner und zugunsten einer mächtigen Verwaltung, die sich der demokratischen und justiziellen Kontrolle entzieht.

Die Bedeutung der Diskussion um Menschen- und Bürgerrechte in Europa kann angesichts dieser Entwicklung gar nicht hoch genug eingeschätzt werden.

Beste Fachlektüre wünscht Ihnen

Oliver Brüchert

\section{TH르는 26}

Hooligans sind das häßliche Gesicht des europäischen Fußballs, sagt man. Berserkern gleich prügeln sie sich untereinander, liefern sich Straßenschlachten mit der Polizei, begehen erhebliche Sachbeschädigungen Gewalttätigkeit um ihrer selbst willen. Die Politik ist zum Handeln entschlossen: Jetzt wird hart durchgegriffen! So werden Gesetze durchgepaukt, die sonst keine Mehrheit fänden. Fußball wird zum Experimentierfeld einer verschärften Sicherheitspolitik.

\section{Wenn aus Fußball Krieg wird}

Von Anton M. van Kalmthout

Warum die Randale meistens ausbleiben

Von Oliver Brüchert 32

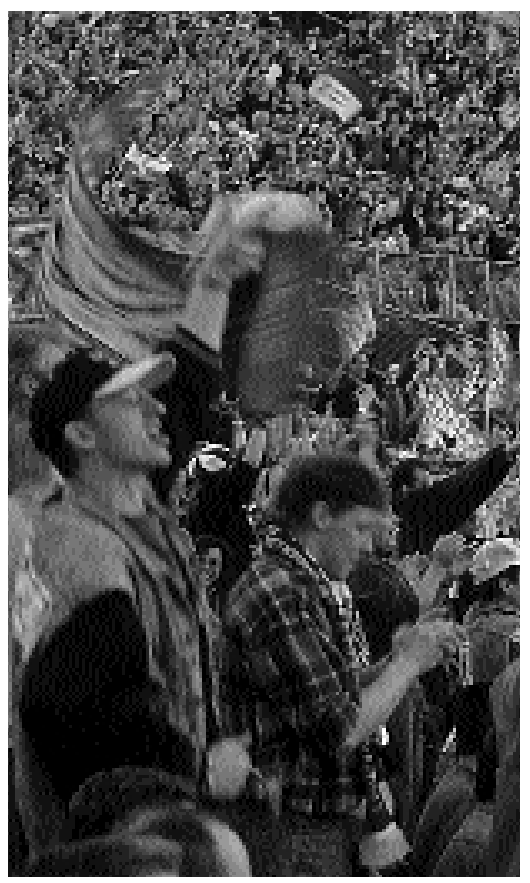

\section{FORUM} S. 12

Gegen die Thesen Rolf Gössners, der im letzten Heft die Kronzeugenregelung insgesamt als Auslaufmodell bezeichnet hat, argumentieren Stefanie Mehrens und Uwe Mühlhoff, daß eine modernisierte Kronzeugenregelung zur Bekämpfung mafiöser Strukturen unentbehrlich sei.

Kronzeugenregelung:

Effektive OK-Bekämpfung!

Von Uwe Mühlhoff und Stefanie Mehrens

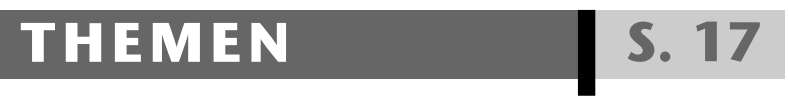

Strafvollzug:

Gefängnis und freier Markt

Von Hartmut-Michael Weber

Europa:

Grenzenlose Strafverfolgung

Von Sabine Gleß und Ursula Nelles. .

\section{MAGAZIN}

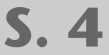

Politik der Einsperrung:

"Bequeme Feinde«

Von Loï J. D. Wacquant

Jugend und Gewalt:

\section{Entwicklungen und Erklärungen}

seit der Wende

Von Klaus Boers

Standpunkt:

Schwimmen gegen den Strom

Helga Einsele zum 90. Geburtstag

Von Bernd Maelicke

\section{Kriminalsoziologische Bibliografie in der Heftmitte}

Beilagenhinweis: Dieser Ausgabe liegt ein Prospekt der Nomos Verlagsgesellschaft bei. Wir bitten freundlichst um Beachtung.
Als Reformerin und "Netzwerkerin « hat Helga Einsele in der bundesdeutschen Kriminalpolitik Bedeutendes erreicht. Ihr neunzigster Geburtstag ist Anlaß, sich an ihrem Mut und ihrer Entschlossenheit im "Kampf für eine menschliche Gesellschaft « ein Beispiel zu nehmen, meint Bernd Maelicke in seinem Standpunkt auf Seite 11.

\section{RUBRIKEN}

Recht ............. 38

Terminal ............. 39

Rezensionen ........... . 40

Neue Bücher . . . . . . . . . . 41

Impressum ........... 42 